\title{
Implementing Forest Pest Management Practices in the USA: Problems and Solutions ${ }^{1}$
}

\author{
by
}

Logan A. Norris²

\begin{abstract}
Implementation of effective pest management strategies in intensive forestry is impeded by educational, technical, administrative, and legal problems. Some of the immediate problems can be solved through improved forestry education and research. Solution of the educational and technical problems, together with relief in the administrative and legal areas, will improve the integration of pest management into intensive forest management programs.
\end{abstract}

Key words: Integrated pest management, weeds, insects, disease, animal damage, education, legislation.

\section{Résumé}

La mise en place de stratégies efficaces d'aménagement forestier intensif contre les ravageurs est entravée par des problèmes d'ordres éducatif, technique, administratif et légal. Quelques-uns des problèmes peuvent être résolus grâce à une recherche et une éducation forestières améliorées. Solutionner les problèmes techniques et éducatifs, tout en allégeant les domaines administratifs et légaux, améliorera l'intégration de l'aménagement contre les ravageurs à l'intérieur de programmes d'aménagement forestier intensif.

Mots clés: Aménagement intégré contre les ravageurs, mauvais herbe, insectes, maladie, dommage par les animaux, éducation, législation.

\section{Introduction}

Weeds, insects, disease organisms and animals are natural inhabitants of the forest, but as pests they can completely disrupt the production of fibre, forage, and other commodities in intensively managed forests. Pest management, which should be an integral part of intensive forest management, is often ignored until pest problems appear, usually in serious proportions. Then pest management is based on reaction to the problem, rather than planned for within the context of the management of the total forest resource. I believe these two concerns should not be separated.

Implementation of pest management practices is impeded by problems that can be divided into four categories: educational, technical, administrative, and legal. These problems are present regardless of the pest involved but vary in

IPaper presented at the joint meeting of the Society of American Foresters and the Canadian Institute of Forestry, working group on Entomology and Pathology, Quebec, Quebec. August 7, 1984 .

2Department of Forest Science, Oregon State University, Corvallis, Oregon 97331 magnitude. For example, technical problems seriously restrict animal damage control because of the lack of good data and an effective research effort. Methods for control of forest insects are quite advanced in comparison. Administrative problems are particularly difficult in the public sector but relatively unimportant in the private sector. In some parts of the country, legal problems have virtually stopped vegetation management with herbicides by the US Department of Agriculture Forest Service and the US Bureau of Land Management. This situation has created social and political problems in the private sector, even without the same legal constraints. In this paper I examine how these problems affect the implementation of forest pest management practices in the USA and suggest some possible solutions.

\section{Educational Problems and Solutions}

\section{Problem}

In professional education, the problem begins with the curriculum for forest managers and pest management spe- 
cialists and continues with the lack of effective continuing education programs for these professionals. All forestry schools offer courses on forest pests, but these are usually taught in specialty departments such as entomology or pathology. With this kind of curriculum, students may have to take four separate courses to learn about the four major pest groups and an additional course in integrated forest pest management. Most schools offer a course in "forest protection," but interviews with those responsible for these courses reveal that pest management is considered outside the context of total forest resource management. As a result, foresters continue to react to pest problems rather than to include pest management in their forest management planning. Some examples of poor planning are timber harvesting that does not account for the needs of the regeneration phase, or regeneration planning that does not allow for adequate site preparation to minimize damage from competing vegetation or animals.

\section{Solution}

We must improve foresters' training in pest management and make it an integral part of forest management. In addition, we must train specialists in integrated forest pest management. Effective coverage of pest management topics is desperately needed in continuing education programs. In recent years, management of competing vegetation has been included in these programs but other aspects of pest management are often missing. The public training programs for silviculture certification offer a good opportunity to bring practicing foresters up to speed

\section{Problem}

In general, the public agrees that some forest land should be managed for commodity production, commensurate with the protection of other resources. But it often fails to recognize that pest management is part of forest management. It is difficult to persuade the public that deer can present a serious forest management problem, to be solved in commercial forests through habitat manipulation, population control, and protective materials or devices.

\section{Solution}

Only through an intensified and continued public education program can public awareness be increased. The current educational programs of the Society of American Foresters (SAF) are a major step in the right direction, and I am convinced they will eventually pay off. We must be sure to include pest management as a necessary refinement to these programs.

\section{Technical Problems and Solutions}

\section{Problem}

The technical problems with forest pest management result from weaknesses in the quantitative data base for decision-making. The weakest areas are in animal damage and diseases. Weed and insect problems are better understood, but more information is needed. These problems will continue as long as pest management research is unevenly funded, poorly coordinated, and lacking in an integrated focus. The present data base does not provide enough specific criteria for managers to determine: (a) the need for treatment, (b) the degree of resource protection or enhancement to achieve, (c) the efficacy of potential programs, and (d) the risks associated with specific control procedures. Without objective criteria, managers must rely on subjective judgment, and may fail to respond to a pest problem in time, thereby losing productivity, or may act unnecessarily, thereby expending scarce resources.

This nonquantitative approach to decision-making is attacked with increasing vigor by those critical of many pest control decisions. They argue that the bias of subjective judgments causes serious errors in decision-making. Highlevel managers in public agencies and reviewers of environmental impact assessments need quantitative data to judge the need for and adequacy of proposed plans of action.

\section{Solution}

This problem can be solved through an effective research effort (discussed below) and a structured, analytical approach to the collection and review of data from various operational programs. There is a tremendous wealth of information collected every year by public agencies and industrial forest land managers. This information includes data on stocking, growth and yield, effect of various pests, and the consequences of pest management strategies. A lack of clear objectives, of uniform procedures for data collection, and of methods for compilation and analysis of the data have prevented the effective use of this powerful resource. The field forester cannot be expected to collect and analyze data. Rather, it is a staff job of significant scope and complexity. The major land-management entities must be prepared to make a new commitment to this effort if it is to succeed.

\section{Problem}

Pest management research in forestry is fragmented and, with a few exceptions, lacks a total-resource orientation. For example, in the US Forest Service, insect and disease research are in one division, weed research in another, and wild life and environmental research in a third. This fragmentation reflects the strong discipline orientation of our educational system. It is not surprising that our management approaches strongly reflect our educational and research orientation.

Funding for pest management research is poor in certain areas such as animal damage and environmental effects. In recent years, funding has improved for accelerated research and development programs on major insect pests such as the Douglas-fir tussock moth, gypsy moth, southern pine beetle, and spruce budworm. Also, a series of administrative studies on vegetation management alternatives has been funded by the National Forest Systems and by major research cooperatives in the Southeast and the Pacific Northwest. The administrative studies will be completed in federal fiscal year 1986.

Research on the environmental impact of pest management strategies, especially nonchemical alternatives, is poorly funded. Consequently, the data base for decisionmaking is weak. Recent decreases in Forest Service and Fish and Wild life Service funding have nearly eliminated research on animal damage. Without this research, animal damage is certain to continue as a major problem in the establishment and management of young stands.

\section{Solution}

The solution to this problem requires two difficult changes. First, pest management research and associated environmental effect research need to be integrated, probably 
by the reorganization of existing research administrative structures and the creation of multidisciplinary research units. Second, funding must be improved, particularly for research on animal damage and environmental effects. This is a tall order in today's economy, but it is a worthwhile investment based on the potentials for pest management identified by Jim Stewart. ${ }^{3}$

\section{Administrative Problems and Solutions \\ Problem}

Administratively, integrated pest management is difficult to implement because of problems that result from the inadequate training for forest managers and pest management specialists and weaknesses in the technical data base. As long as managers must rely on subjective judgments, selection of the "personal favorite" is inevitable.

\section{Solution}

This problem can only be solved from the ground up, i.e., field professionals learn to recognize and develop methods for integrated pest management. Then they must take the necessary administrative actions for implementation of these procedures. Clearly, the educational and technical problems must be solved before the administrative problems can be dealt with.

\section{Problem}

A more difficult administrative problem is the cumbersome procedure required by the National Environmental Policy Act (NEPA) for development of pest management programs. NEPA, although not without its advantages, has greatly increased the time and cost of initiating action programs in federal agencies and in federally funded programs. A survey among pest management officials in the Forest Service indicates preparation of an environmental assessment takes from 3 to 15 months, usually 1 year. Environmental impact statements require 18 months to 2 years, if there are no lengthy appeals. Thus, to achieve the best solution in cost and effectiveness, the problem must be identified 1 to 2 years before action is needed. The present technical data base is weak for this purpose.

The cost of preparing these documents is surprisingly high. In a brief survey conducted in the Forest Service Office of Pest Management ${ }^{4}$, the cost of preparing nine environmental assessments ranged from $\$ 500$ to $\$ 73000$, with an average cost of $\$ 24750$. The cost of preparing environmental impact statements was higher, ranging from $\$ 7000$ to $\$ 450000$, with an average cost of $\$ 111188$. These figures usually do not include overhead or all salary costs, and costs rise when there are appeals. In 1983, the Forest Service responded to about 500 administrative appeals (not all pestrelated). The total cost of these appeais was $\$ 6.5$ million, or $\$ 13000$ per appeal.

\section{Solution}

This administrative problem will be difficult to solve without legislative relief, although some improvement is possible by changing Council for Environmental Quality (CEQ) rules

\footnotetext{
${ }^{3}$ See following paper in this issue.

4August 1, 1984, Memo to the Record, Dennis R. Hamel, USDA Forest Service, Office of Pest Management, Washington, D.C.
}

and guidelines. I believe it is time to review CEQ rules and guidelines with a cost-benefit analysis. Cumbersome procedures that have no demonstrated benefit should be eliminated. Streamlining the CEQ rules may also reduce the cost of handling appeals.

\section{Legal Problems and Solutions}

\section{Problem}

The largest number of legal problems associated with pest management concern compliance with administrative rules, such as those set forth by NEPA. Other legal problems involve allegations of harm caused by pest management practices, but evidence of significant harm is lacking.

Almost all cases involving federal agencies have concerned NEPA compliance. In early cases, the courts ruled that the environmental impact statements did not contain all of the relevant information. In some other cases, they ruled that failure to mention the existence of scientific uncertainty may have prevented a reasoned decision. Most issues concerned exposure and toxicology. The problems were solved by expanding the scope of information included in the environmental impact statements.

The 40 Codified Federal Regulations (1502.22) provide that an agency must prepare a worst-case analysis if, in evaluating significant adverse effects on the human environment, there are gaps in relevant information or scientific uncertainty. In the most recent cases on herbicide use, federal judges have ruled that worst-case analyses were required.

The position of the Forest Service and the Bureau of Land Management has been that registration of pesticides according to the Federal Insect Fungicide and Rodenticide Act (FIFRA) was sufficient to establish that the proposed material was both effective and safe when used according to directions on the label. Judges in the 9th District Circuit Court have consistently ruled that this registration is insufficient. According to the courts, public agency policies are inconsistent with NEPA. The government has lost several cases, leaving difficult precedents and, equally important, a negative public impression of pest management programs.

\section{Solution}

The solution to this problem has two parts. First, the Environmental Protection Agency (EPA) must clarify the meaning of a pesticide registration. During recent Forest Service cases, EPA officials would not testify on this subject, and the courts and forest managers are unsure whether safety considerations are adequately dealt with in FIFRA pesticide regulations. Second, the $C E Q$ regulations on worst-case analyses must be clarified. The present interpretation by the courts is that any level of uncertainty requires a worst-case analysis, and individual definitions of the "worst case" range from the probable to the ludicrous. In August 1983, CEQ offered some worst-case analysis guidelines for review in the US Federal Register. These would have provided the solution, but were withdrawn for future consideration.

The Oregon Society of American Foresters recently adopted a position statement that urges the EPA and the CEQ to take the action suggested above. This issue is of national importance, and I recommend a similar statement be adopted by the national SAF. Clarification of these two issues will provide major relief to beleaguered federal pest management 
programs, particularly to those concerned with use of herbicides in forestry.

\section{Problem}

In the private sector, most of the suits that have been filed concern technical issues such as toxicology and exposure. Only in rare cases have the courts substantially upheld plaintiff claims. Perhaps the most intensively argued case occurred in 1983 in the Supreme Court of Nova Scotia, between a coalition of concerned citizens and Nova Scotia Forest Industries. Plaintiffs charged that the proposed application of 2,4-D and $2,4,5-T$ in Nova Scotia forests would cause significant health risks for nearby inhabitants.

Technical experts worldwide were called in by both parties. Direct and cross-examination took 21 days of court time. The examination of technical issues concerning vegetation management, especially with herbicides, was exhaustive. The court ruled in favor of Nova Scotia Forest Industries and noted that "if, indeed, there is a risk at all, (it) is infinitesimally small and many, many times less than one in a million." 5 It is significant that in this case in which technical issues were the focus and were explored in great depth, the court ruled that the proposed herbicides were safe.

Besides having different bases in law, public and private cases have another important difference. To my knowledge, fewer legal resources are committed to public than to private cases, and public cases are prosecuted less intensively. For example, in the Nova Scotia case, three defense attorneys were on site full-time during the case and for three months during its preparation. These attorneys were quite familiar with the legal and technical issues involved. In Forest Service cases, the USDA General Council assigns an attorney to work on the case, but another attorney from the US Justice Department prosecutes the case. These federal attorneys have a limited amount of time to prepare a case and the cases assigned them often have no continuity in subject matter. Their cases can vary weekly, involving such diverse subjects as timber trespass, 2,4-D, and fraudulent mining claims.

My criticism is directed not toward the attorneys but toward the level of resource the government is allocating to these cases. Often there is no parity between the level of

\footnotetext{
5A copy of the opinion of Justice Nunn on this case is available from the USDA Forest Service. Office of Pest Management, P.O. Box 2417. Washington, D.C. 20013. Reference, PesticideUse Advisory Memorandum No. 344. Copies are also available from the Nova Scotia Depart. ment of Lands and Forests, 523 Prince St., Truro, N.S. B2N 5B8.
}

technical resource involved and the level of legal resource allocated. In two recent cases, the cost to the Forest Service was more than $\$ 50000$, exclusive of costs for Justice Department attorneys. The Globe, Arizona case cost $\$ 250000$ exclusive of out-of-court settlement fees and Justice Department costs. There are 15 cases in current litigation. If we are going to decide natural resource issues in the courts, we must mobilize legal resources commensurate with the technical resources and the magnitude of the issue.

\section{Solution}

This problem is particularly difficult to solve within the existing structure. We need to allocate more legal resources to these cases, but in addition the attorneys must be almost as knowledgeable in the technical issues as the experts they will examine. In addition, government attorneys need greater continuity in their assignments. It is equally important that they ensure that the government's case addresses exactly the legal issues involved. This may sound obvious, but it hasn't always happened.

Several law firms have become expert in the prosecution of pest management cases. Perhaps the US Department of Agriculture, the US Department of the Interior, and the US Justice Department could contract for these firms to assist in preparing and defending government cases. Intervenors could also employ these firms. Hopefully, implementation of my other solutions will decrease the amount of time we spend in court, but meanwhile let's increase our chance of winning by putting more legal muscle into our efforts.

\section{Conclusions}

Pest management is an important part of intensive forest management, but its implementation is difficult because of educational, technical, administrative, and legal problems. Fortunately, some of the more pressing problems will be the easiest to solve because they involve foresters, forestry education, and forestry research. Including pest management in our professional curriculum and continuing education programs will better prepare our managers and specialists to consider pest management as part of intensive forest management. Improved coordination and funding of research will provide a better technical base for quantitative decisionmaking. Substantive progress in these two areas, together with even modest improvements in the administrative and legal areas, will greatly improve our ability to implement pest management practices in intensive forestry in the USA. 